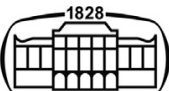

AKADÉMIAI KIADÓ

Journal of Behavioral Addictions

9 (2020) 4, 1032-1043

DOI:

$10.1556 / 2006.2020 .00098$

(c) 2020 The Author(s)

\title{
A network analysis of problematic smartphone use symptoms in a student sample
}

\author{
SHUNSEN HUANG ${ }^{1}$, XIAOXIONG LAI ${ }^{1}$, YE XUE $^{1}$, \\ CAI ZHANG ${ }^{2}$ and YUN WANG ${ }^{1 *}$ @
}

\footnotetext{
${ }^{1}$ State Key Laboratory of Cognitive Neuroscience and Learning, Beijing Normal University, Beijing, China

${ }^{2}$ Collaborative Innovation Centre of Assessment Toward Basic Education Quality, Beijing Normal University, Beijing, China
}

Received: April 14, 2020 - Revised manuscript received: August 1, 2020; October 9, 2020; November 7, 2020;

November 13, 2020 • Accepted: November 30, 2020

Published online: December 24, 2020

\section{FULL-LENGTH REPORT}

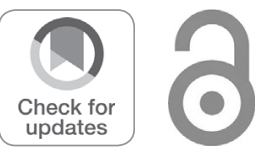

*Corresponding author.

E-mail: wangyun@bnu.edu.cn

\begin{abstract}
Background and aims: Previous research has established risk factors for problematic smartphone use (PSU), but few studies to date have explored the structure of PSU symptoms. This study capitalizes on network analysis to identify the core symptoms of PSU in a large sample of students. Methods: This research investigated 26,950 grade 4 students $($ male $=13,271)$ and 11,687 grade 8 students (male $=$ 5,739 ) using the smartphone addiction proneness scale (SAPS). The collected data were analyzed using a network analysis method, which can provide centrality indexes to determine the core symptoms of PSU. The two networks from the different groups were compared using a permutation test. Results: The results indicated that the core symptoms of students' problematic smartphone use were the loss of control and continued excessive use across the two samples. Discussion and conclusions: These findings suggest that loss of control is a key feature of problematic smartphone use. The results also provide some evidence relevant to previous research from the perspective of network analysis and some suggestions for future treatment or prevention of students' problematic smartphone use.
\end{abstract}

\section{KEYWORDS}

network analysis, problematic smartphone use, core symptom, loss of control

\section{INTRODUCTION}

With the advent of the media age, smartphones are becoming widely popular among people of all ages. According to the 44th statistical report on the development of the Internet in China issued by the China Internet Network Information Center (CNNIC), 99.1\% of Chinese Internet users access the Internet through smartphones, and $20.9 \%$ of Internet users are under the age of 19 (CNNIC, 2019). Smartphones could provide a wide range of functions, including surfing information, communication, education, and entertainment, but they might represent a potential risk factor for teenagers who overuse and become dependent on them. Longitudinal research based on young adults and adolescents revealed that excessive problematic smartphone use (PSU) is a risk factor for mental health outcomes (Lapierre, Zhao, \& Custer, 2019; Thomée, Härenstam, \& Hagberg, 2011). Karsay, Schmuck, Matthes, and Stevic (2019) also found that the excessive use of smartphones can predict the subsequent stress of users with little online self-disclosure. Cross-sectional research has also shown that adolescent PSU is associated with a series of psychological and behavioral problems, such as poor sleep quality (Lee et al., 2017; Liu et al., 2017; Soni, Upadhyay, \& Jain, 2017), depression or anxiety (Kim et al., 2019; Seo, Park, Kim, \& Park, 2016; Yang, Zhou, Liu, \& Fan, 2019), decreased academic performance (Seo et al., 2016), loneliness and poor social relationships (Yayan, Suna Dağ, \& Düken, 2019), cybersexual delinquency (Choi, Choi, \& Kim, 2017), hypertension (Zou, Xia, Zou, Chen, \& Wen, 2019), and increased aggression (Um, Choi, \& 
Yoo, 2019). Researchers have argued that the problematic smartphone use of adolescents suffering from negative impacts must be urgently controlled or prohibited (Seo et al., 2016). Nevertheless, it is very important to help them use smartphones reasonably and prevent them from the adverse effects of problematic smartphone use.

\section{Concept of problematic smartphone use (PSU)}

Regarding the negative effects of using smartphones, researchers often use the concept of problematic smartphone use and smartphone addiction. Some researchers use the term "smartphone addiction" (see Lee, Ahn, Choi, \& Choi, 2014), whereas others use the term "problematic smartphone use" (see Busch \& Mccarthy, 2020). However, Billieux, Maurage, Lopez-Fernandez, Kuss, and Griffiths (2015) argued that little evidence exists that supports PSU as a kind of addictive behavior. Panova and Carbonell (2018) also reviewed the literature and found that studies that focused on smartphone addiction found that it did not meet the diagnostic criteria of addiction; for example, smartphones are just a medium for people to engage in specific behaviors (such as playing games and visiting Internet sites), allowing researchers to believe that the term "smartphone addiction" should be used with caution. As Montag, Wegmann, Sariyska, Demetrovics, and Brand (2019) pointed out, given the widespread use of smartphones in our daily lives, some researchers understandably use the term "smartphone addiction." However, in this study, we followed suggestions by previous researchers (Billieux, Schimmenti, Khazaal, Maurage, \& Heeren, 2015; Panova \& Carbonell, 2018) and use the term "problematic smartphone use." According to previous researchers, PSU refers to compulsive and dependent use that interferes with the user's daily life (Horwood \& Anglim, 2018).

\section{Symptoms of problematic smartphone use}

Although many research results on the potential prevention and treatment of PSU have been accumulated, no consensus exists on the symptoms of PSU. Many researchers have constructed the concept of PSU in the frame of addiction (Panova \& Carbonell, 2018) according to behavioral addiction or substance addiction (see Kim, Lee, Lee, Nam, \& Chung, 2014; Kwon, Kim, Cho, \& Yang, 2013; Leung, 2008). These concepts and related scales present many symptoms of PSU. The American Psychiatric Association's Diagnostic and Statistical Manual of Mental Disorders 5 (DSM-5) proposed that the criteria for Internet gaming disorder consist of preoccupation with Internet games, withdrawal symptoms, tolerance, inability to control use, loss of interests in other things, continued excessive use, deception of family members, and jeopardizing a relationship or education (APA, 2013; Tao et al., 2010). Based on one review, Gutiérrez, de Fonseca, \& Rubio (2016) pointed out that the criteria for smartphone addiction include difficulty to control, tolerance, unease (anxiety or depression) after abstinence, and social and family conflicts. These symptoms are very similar to the symptoms of Internet gaming disorder, which exert a negative influence on daily life. Researchers believe that these disorders can be conceptualized as a system of causally connected core symptoms or typical core behaviors rather than the effects of a latent disorder (Borsboom \& Cramer, 2013).

For behavioral addictions such as gaming addiction, the central or key symptom is the loss of control (see ICD-11 (WHO, 2020)). From the perspective of neuropsychology, Brand, Young and Laier (2014) proposed a theoretical model of generalized and specific Internet addiction, emphasizing the key role of the control process in the development of Internet addiction. Moreover, the Person-Affect-CognitionExecution (I-PACE) model of addictive behaviors (such as gambling, gaming, buying-shopping, and compulsive sexual behavior disorders) also emphasizes the importance of inhibitory control (Brand et al., 2019). However, the central or core symptoms of PSU remain unclear, and robust evidence is needed to prove whether the core symptom of PSU is the loss of control. From the perspective of semiology (Borsboom \& Cramer, 2013), distinguishing the core symptoms of PSU can promote an understanding of its characteristics, which is of significance for its prevention and treatment.

\section{Network analysis between symptoms}

Network analysis is a method to visualize the structure and interactions of various variables, different personality traits (Marcus, Preszler, \& Zeigler-Hill, 2018), or multiple symptoms in clinical psychology (Borsboom \& Cramer, 2013). In the network, nodes usually represent the observed variables of potential factors or different personality traits and form a complete visual graph through edge connections to describe the relationship among observed variables, traits, or symptoms. Therefore, based on the corresponding centrality (such as the closeness, betweenness, and strength of nodes, the highest centrality represents the most important symptom, namely, the core symptom), the network can indicate the symptoms or observed variables that are the core, that is, which have the most important impact on the entire network (Borsboom \& Cramer, 2013; Marcus et al., 2018; Smith, Lee, Martel, \& Axelrad, 2016). The core symptoms in a network may be the most influential factors in the generation or maintenance of the disorders (Borsboom \& Cramer, 2013; Martel, Levinson, Langer, \& Psychiatry, 2017). Therefore, interventions of core symptoms will be more effective than that of peripheral symptoms, maximizing the impact of interventions of other behaviors or symptoms connected with core symptoms (Beard et al., 2016; Levinson et al., 2017) and preventing disorders from getting worse (Borsboom \& Cramer, 2013).

In recent years, this method has been widely used in the study of personality and clinical psychology. For example, Marcus et al. (2018) explored the network of the "dark" personality trait and found that interpersonal manipulation and callousness were central traits in the network. Levinson and his colleagues (2017) investigated the core symptoms of bulimia nervosa, anxiety, and depression and found that fear 
of weight gain is the core symptom, suggesting that future exposure treatment should focus on this core symptom. Similarly, network analysis could also be used to distinguish the core symptoms of PSU, which would be instructive for the development of interventions.

\section{Present study}

This study analyzed responses to the smartphone addiction proneness scale developed by Kim et al. (2014). Their scale was developed based on a subsample of adolescents (elementary, middle, and high school students) and reveals symptoms similar to behavioral addiction symptoms and unique characteristics of smartphones, such as applications, online services, and sensory features. Therefore, this scale is suitable for this study. The purpose of this study is to determine the core symptoms of PSU through a network analysis and to provide a basis and suggestions for future research on and interventions of PSU. Based on this scale and the network analysis, this study explored the core symptoms of PSU in students in grades 8 and 4 and further compared whether a global strength difference exists between the two networks obtained through students in different grades.

\section{METHODS}

\section{Participants and procedure}

From 2017 to 2018 , a total of 51,115 grade 4 students and 26,207 grade 8 students from two provinces in China participated in this investigation. The procedure was as follows. Teachers helped guide students in filling out the questionnaires in class. The teacher read the instruction to students, and students independently completed the corresponding questionnaires. During this process, if the students could not understand the items, the teacher explained the meaning of the sentences and then responded by themselves. Among the grade 4 students, 20,120 students who did not own a smartphone and 4,045 students whose data were missing were excluded from this study, and 26,950 students' data were used (male $=13,271$ ). Among the grade 8 students, 6,635 students who did not own a smartphone and 7,885 students whose data were missing were excluded from this study, and 11,687 students' data were used (male = 5,739 ). Students' age information was not available for us because this program did not contain such information. However, based on the Compulsory Education Law of China, every child should attend primary school at the age of six and complete the nine-year compulsory education. Therefore, students in grade 4 and grade 8 are around 9-10 years old and 13-14 years old, respectively. Other detailed demographic materials are presented in appendix I.

\section{Measurement}

Students' PSU was evaluated using a modification to the Smartphone Addiction Proneness Scale developed by Kim et al. (2014). The modified PSU scale consisted of 4 dimensions: (1) disturbance of virtual life; (2) virtual life orientation; (3) withdrawal; and (4) tolerance. Each dimension contained 4 items that are rated on a 4-point scale. In this study, confirmatory factor analysis (CFA) of the grade 4 students' PSU scores revealed good structural validity (comparative fit index (CFI) $=0.952$, Tucker Lewis index $(\mathrm{TLI})=0.941$, and root mean square error of approximation (RMSEA) $=0.068$ (90\% CI $(0.067,0.069)$ ), and the CFA of grade 8 students' PSU also showed favorable structural validity $(\mathrm{CFI}=0.936$, TLI $=0.941$, $\mathrm{RMSEA}=$ 0.075 (90\% CI $(0.074,0.077))$. Cronbach's $\alpha$ was 0.941 and 0.936 for grade 4 and grade 8 students, respectively.

In this study, the dimensions representing symptoms (e.g., tolerance) in the original scale were not used, and the functions or meanings reflected by each item were regarded as symptoms for two reasons. One is that the symptoms reflected by the dimensions actually cannot fully reveal the meaning of the symptoms. For example, the items measuring tolerance (Kim et al., 2014) actually measure loss of control and continued excessive use (Panova \& Carbonell, 2018) and fail to measure the full meaning of tolerance because of the complexity of the operation and conceptualization of tolerance (Billieux, Maurage, et al., 2015; Billieux, Schimmenti, et al., 2015). Starcevic (2016) also pointed out that increased activity engagement and the need for better devices in behavioral addictions do not necessarily reflect tolerance. The other reason is that the frameworks of many problematic smartphone use scales are based on behavioral addiction (such as Internet addiction or Internet gaming disorder) (Kim et al., 2014; Leung, 2008), which indicates that the items of these scales should also reflect the meaning of the symptoms that are similar to behavioral addiction. Consequently, according to the behavioral addiction criteria in ICD-11 and DSM-5, as well as other references, the meanings or functions of each item are determined and regarded as symptoms of PSU (see appendix II for all items, identified symptoms, and corresponding references).

\section{Analytical procedure}

SPSS 20.0 and Rstudio 3.4.4 software were used to analyze our data. First, SPSS 20.0 software was used to manage and preprocess our data. Second, to reduce the complexity and increase the accuracy of networks (Friedman, Hastie, \& Tibshirani, 2008), a graphical LASSO network was used to construct the network. For the network analysis, several indexes, including centrality (betweenness, closeness, strength), small-worldness index (SWI), and clustering coefficients, were used to evaluate the network's function. Betweenness refers to the frequency at which a node is the shortest path between two other nodes. Closeness is the inverse of the total length of all short path lengths (SPLs) between one node and all other nodes in the network. The strength for a node is the sum of the partial correlations between the node and the other nodes in the network (Marcus et al., 2018); a higher strength represents a stronger 
influence of the activation of one node on the other nodes. The small-worldness index (SWI) can be defined as a network's tendency to have both a high clustering coefficient and a short average path length (Costantini et al., 2015). When the SWI is greater than 1 under unrestricted conditions (a borderline value) (or greater than 3 under strict conditions), the network has the small-worldness property (Costantini et al., 2015; Humphries \& Gurney, 2008), which means that any node can reach any other node in only a few steps, and symptom activation will spread quickly in the network (Borsboom \& Cramer, 2013; Borsboom, Cramer, Schmittmann, Epskamp, \& Waldorp, 2011). The clustering coefficients are used to determine whether a node is redundant or artificially inflated (Costantini et al., 2015; Marcus et al., 2018). In this study, the "signed" Zhang coefficient was used to calculate cluster coefficients because it can be used in correlational data and considers the negative edge weights (Zhang \& Horvath, 2005). Finally, the networks' global strength (overall connectivity) between grade 8 and grade 4 students, defined as the weighted absolute sum of all edges in the network, were compared using a permutation test, which has also been called the network comparison test (Van Borkulo et al., 2015). The permutation test determined whether the global strength difference between the two networks was more extreme than 95\% ( $\alpha=$ 0.05) on a null distribution (Van Borkulo et al., 2015; Van Borkulo, Boschloo, Kossakowski et al., 2017). The null hypothesis for the two networks was that the networks of the grade 8 and grade 4 students were equal. In addition, to guarantee the quality and accuracy of the comparison test (Van Borkulo, Boschloo, Kossakowski et al., 2017), 5,000 permutations were performed. Although we calculated cluster coefficients before we performed the network analysis, we also performed a redundancy analysis for the questionnaire items, as suggested by Christensen, Golino, \&
Silvia (2020). Our results based on the "Bonferroni" method revealed no redundant items; however, based on the "adapt" method, the results showed that some redundant items exist across different dimensions in this PSU questionnaire for both grade 4 and grade 8 students. However, we did not combine these redundant items because each item represents different criteria related to behavioral addiction in the DSM5. The $\mathrm{R}$ package agraph (version 1.6.4) was used for the network analysis, the $\mathrm{R}$ package NetworkComparisonTest (version 2.2.1) was used for the network comparison, and the $\mathrm{R}$ package EGAnet (version 0.9.6) was used for the redundancy analysis.

\section{Ethics}

Data for this study were collected as part of the "Regional Assessment of Education Quality (RAEQ)" of Beijing Normal University. This study was approved by the Beijing Normal University Research Ethics Committee. All students involved in the survey, as well as parents and schools, provided oral consent, which was in line with the code of ethics approved by AERA (2011) and the Declaration of Helsinki.

\section{RESULTS}

\section{GLASSO network of grade 8 students}

The graphical LASSO network related to PSU for grade 8 students is presented in Fig. 1. The direct or indirect connections of different nodes mean that different symptoms interacted. In this network, nodes I1 (jeopardize education), I2 (excessive use), I3 (jeopardize a significant relationship), and I4 (distraction) are indirectly connected through node I15 (loss of control) and node I14 (loss of control). Node I4 (distraction) has a strong and indirect connection with node

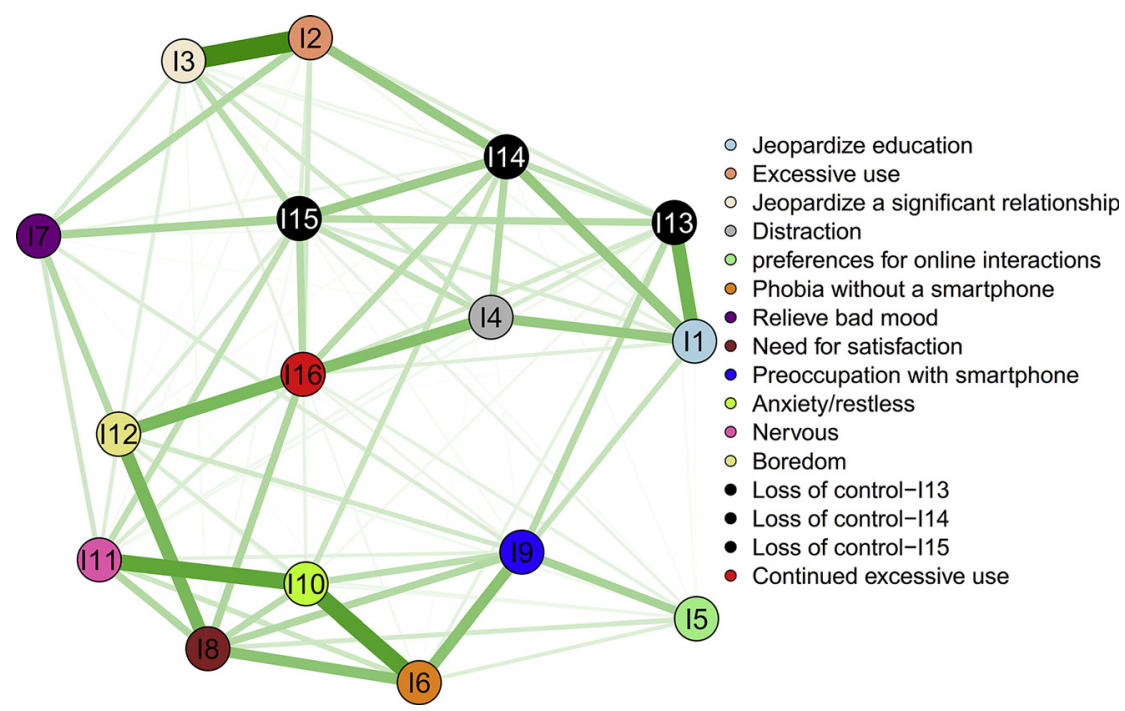

Fig. 1. GLASSO network related to PSU in grade 8 students. Note. Nodes I1-I16 represent the items of the scale used. Lines between nodes are called edges or paths, and a thicker edge means higher connectivity or intensity between the nodes. The partial correlation matrix from grade 8 students is included in Appendix III 
I12 (boredom) through node I16 (continued excessive use). A similar pattern was observed with I7 (relieve bad mood) in that it had a connection with the entire network through other nodes, such as I15 (loss of control), I12 (boredom), and I2 (excessive use). Figure 1 also reveals the edge intensity between different nodes. Nodes I3 (jeopardize a significant relationship) and $\mathrm{I} 2$ (excessive use) have the strongest edge intensity with each other, and node I10 (anxious/restless) also has strong relationships with $\mathrm{I11}$ (nervous) and I6 (phobia without a smartphone). The small-worldness index for grade 8 students was 1.003, indicating that this network may have a small-world property in the unrestricted condition.

\section{Central symptoms of PSU in grade 8 students}

Further results in Table 1 show that node I14 (loss of control) had the highest betweenness (14) and closeness (0.0055), node I15 (loss of control) had the second-highest closeness (0.0054) and strength (1.06), and node I16 (continued excessive use) had the highest strength (1.18) and the thirdhighest closeness (0.0053). Therefore, I14, I15, and I16 should be the central symptoms of the entire network. In addition, node I10 (anxiety/restless) (betweenness $=10$, closeness $=0.0050$, strength $=1.05$ ) and node $\mathrm{I} 12$ (boredom) (closeness $=0.0053$, strength $=1.01$ ) also enjoyed tenable centrality, which may be next only to the central symptoms (I14, I15, I16). Although node I9 (preoccupation with a smartphone) had the highest betweenness (14), its closeness and strength were relatively low. Node I8 (need for satisfaction) (cluster coefficient $=0.087$ ) was ranked as the first high clustering coefficient, which means that this symptom may have been redundant and captured information that was already measured by the other item.

\section{GLASSO network of grade 4 students}

Figure 2 shows the graphic LASSO network related to PSU for grade 4 students. In this graph, nodes I1 (jeopardize education), I2 (excessive use), and I4 (distraction) are indirectly connected, relying on I14 (loss of control) and I13 (loss of control). Nodes I5, I6, I7, and I8 have few direct connections (e.g., node I7 (relieve bad mood) indirectly connected with node I8 (need for satisfaction) through node I12 (boredom)). These results indicated that the nodes representing different symptoms may rely on other symptoms. Additionally, regarding the network edges, the edge between I2 (excessive use) and I3 (jeopardize a significant relationship) was the strongest across the network. The edges between I11 (nervous) and I10 (anxious/restless), I10 (anxious/ restless) and I6 (phobia without a smartphone), I12 (boredom) and I8 (need for satisfaction), I12 (boredom) and I16 (continued excessive use), I16 (continued excessive use) and I4 (distraction), and I1 (jeopardize education) and I13 (loss of control) were also strong. Moreover, the smallworldness index of grade 4 students was 1.002, indicating that this network may have small-world property in the unrestricted condition.

\section{Central symptoms of PSU in grade 4 students}

Table 1 reveals that I14 (loss of control) has the highest betweenness (20) and closeness (0.0053), that I16 (continued excessive use) has the second-highest closeness (0.0052) and the strongest strength (1.16), and that I15 (loss of control) has the highest closeness (0.0053) and the third-strongest strength (1.06). The high centrality of nodes I14, I16, I15 indicates that the core symptoms of this network are the loss of control and continued excessive use. Besides, node I10 (anxiety/restless) (betweenness $=10$, closeness $=0.048$,

Table 1. Centrality problematic smartphone use network in grade 8 students

\begin{tabular}{|c|c|c|c|c|c|c|c|c|}
\hline & \multicolumn{4}{|c|}{ Grade 8} & \multicolumn{4}{|c|}{ Grade 4} \\
\hline & Bet & Clo & Str & Cluster & Bet & Clo & Str & Cluster \\
\hline I1 & 12 & 0.0052 & 0.87 & 0.068 & 11 & 0.0048 & 0.83 & 0.065 \\
\hline $\mathrm{I} 2$ & 8 & 0.0042 & 0.92 & 0.053 & 10 & 0.0041 & 0.92 & 0.060 \\
\hline I3 & 1 & 0.0039 & 0.85 & 0.060 & 0 & 0.0037 & 0.79 & 0.069 \\
\hline I4 & 4 & 0.0048 & 0.86 & 0.084 & 3 & 0.0046 & 0.88 & 0.076 \\
\hline I6 & 11 & 0.0053 & 1.01 & 0.085 & 5 & 0.005 & 1.05 & 0.080 \\
\hline I7 & 4 & 0.0046 & 0.65 & 0.064 & 4 & 0.0046 & 0.74 & 0.062 \\
\hline I8 & 11 & 0.0052 & 1.03 & 0.087 & 14 & 0.005 & 0.99 & 0.082 \\
\hline I9 & 14 & 0.0047 & 0.91 & 0.069 & 15 & 0.0043 & 0.84 & 0.074 \\
\hline I10 & 10 & 0.0050 & 1.05 & 0.078 & 10 & 0.0048 & 1.04 & 0.077 \\
\hline I11 & 3 & 0.0047 & 0.92 & 0.074 & 3 & 0.0042 & 0.92 & 0.072 \\
\hline I12 & 5 & 0.0053 & 1.01 & 0.066 & 6 & 0.0052 & 1.06 & 0.066 \\
\hline I14 & 14 & 0.0055 & 1.01 & 0.070 & 20 & 0.0053 & 1.03 & 0.065 \\
\hline I15 & 10 & 0.0054 & 1.06 & 0.061 & 6 & 0.0053 & 1.06 & 0.061 \\
\hline I16 & 8 & 0.0053 & 1.18 & 0.063 & 11 & 0.0052 & 1.16 & 0.065 \\
\hline Mean & 7.94 & 0.0048 & 0.92 & 0.071 & 8 & 0.0046 & 0.92 & 0.069 \\
\hline
\end{tabular}

Note: Bet $=$ Betweenness, Clo $=$ Closeness, Str $=$ Strength, Cluster $=$ signed Zhang clustering coefficient, Disturbance $=$ Disturbance of adaptive function, Virtual $=$ Virtual life orientation, Mean $=$ average of 16 items. 


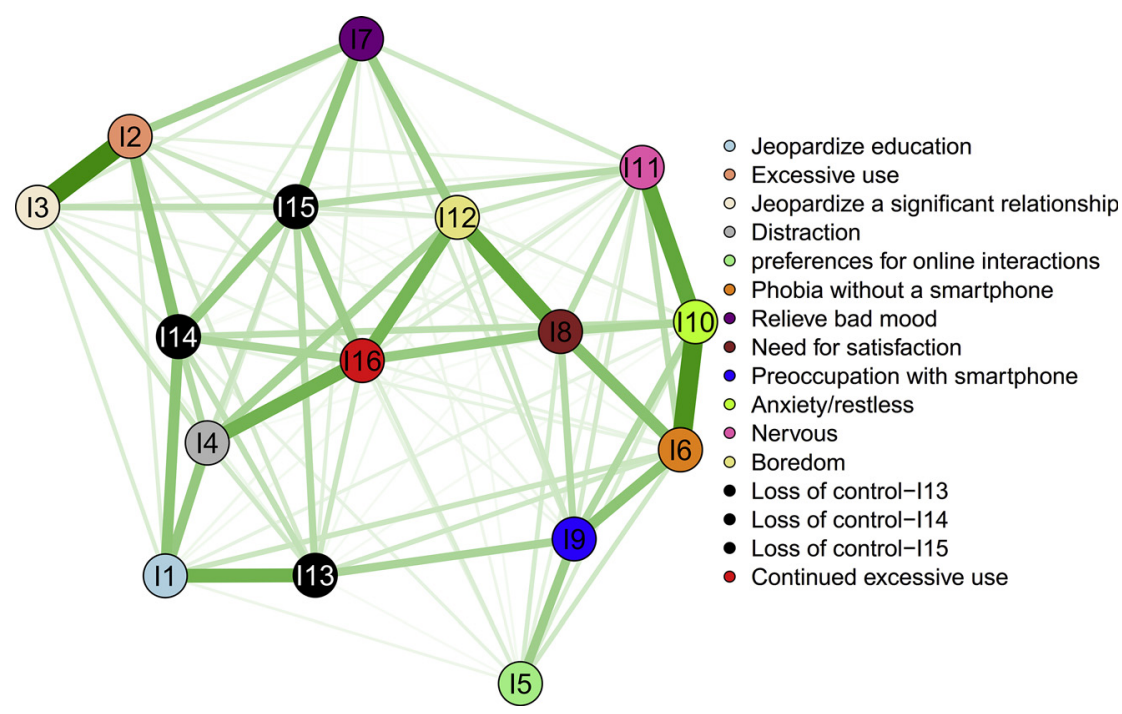

Fig. 2. GLASSO network related to PSU in grade 4 students. Note. Nodes I1-I16 represent the items of the scale used. Lines between nodes are called edges or paths, and a thicker edge means higher connectivity or intensity between nodes. The partial correlation matrix from grade 4 students is included in Appendix IV

strength $=1.04)$ and node I12 (boredom) (closeness = 0.0052 , strength $=1.04$ ) also show considerable centrality in this network, revealing that the two nodes may be the symptoms next to the central symptoms (I14, I16, I15). Node I8 (need for satisfaction) (cluster coefficient $=0.082$ ) has the highest clustering coefficients, which means that this typical behavior may have been redundant.

\section{Comparison of networks between grade 8 students and grade 4 students.}

The network comparison test on global strength invariance showed that the network connectivity among grade 8 students (statist $=7.33$ ) was similar to the network connectivity among grade 4 students (statist $=7.35, P>0.05$ ).

\section{DISCUSSION}

Based on the network analysis of the PSU scale, this study explored the central or core symptoms of students' PSU across different groups. Moreover, the global strength (network connectivity) of the grade 4 and grade 8 students' networks was compared to determine whether the network connectivity was invariant across groups.

Primarily, this study revealed that the core symptoms of PSU are loss of control (I14, I15) and continued excessive use (I16) among grade 4 and grade 8 students. This result is consistent with the criteria of gaming disorder in ICD-11 that stress the key role of loss of control and is consistent with the behavioral addiction model proposed by Brand et al. (2014) (also see Brand et al., 2019). This behavioral addiction model highlights the main role of the prefrontal control process in the development of Internet addiction or other behavioral disorders. Therefore, loss of control is more important than other symptoms, such as anxiety, loneliness, or jeopardizing education, closely related to other symptoms, and in the core position. In addition, why are the core symptoms the same in both samples? One explanation may be their stable self-control ability. A study that analyzed national longitudinal data found that $84 \%$ of adolescents had very stable self-control ability between the ages of 7 and 15 (Hay \& Forrest, 2006). This stable development of selfcontrol ability may explain the similarity of core symptoms among students of different ages. From the perspective of network analysis, this result also provides evidence for previous studies that excessive screen time on smartphones may be more likely to trigger PSU (Soni et al., 2017) and that adolescents with high self-regulation or self-control may be less likely to develop PSU (Deursen, Bolle, Hegner, \& Kommers, 2015; Hormes, Kearns, \& Timko, 2014; Jeong, Kim, Yum, \& Hwang, 2016; Kim, Min, Min, Lee, \& Yoo, 2018). Therefore, how to reduce students' excessive PSU and strengthen the self-control of those with PSU should be prioritized in future prevention and treatment.

Second, the results also showed that symptoms (nodes) in the network were intensively connected in both samples. For example, I12 (boredom) may affect I16 (continued excessive use) (previous studies have demonstrated that boredom proneness can predict an increase in smartphone use time (Al-Saggaf, MacCulloch, \& Wiener, 2018; Matic, Pielot, \& Oliver, 2015; Schroeter, Oxtoby, Johnso, \& Steinberger, 2015)) and then exert influence on I4 (distraction) (Shrivastava and Shrivastava (2014) point out that frequent smartphone use can positively predict distraction). In addition, the small-worldness index also indicated the interaction of different nodes, which may provide a new perspective for the PSU scale. This new perspective is different from traditional ways in which the symptoms of different dimensions (the scale used in this study is 4-dimensions, see Kim et al., 2014) are separated from each other (Borsboom \& Cramer, 2013). 
Finally, this research has some strengths. This study is the first to explore the network structure related to PSU in adolescents. This study explored the core symptoms of students' PSU and may provide some advice on how to prevent students from developing PSU or to treat adolescents with high levels of PSU. According to the function of core symptoms in disorder-related networks, intervention or treatment of core symptoms can reduce the performance of related symptoms and maximize the impact of the intervention of other symptoms (Beard et al., 2016; Levinson et al., 2017). Therefore, in the clinical treatment of PSU, we should first pay attention to the cultivation of self-control ability, eliminate the relationship between users and smartphones, and reduce the mobile phone use time of people addicted to smartphones. Second, attention should be paid to the negative feelings (such as anxiety/restlessness and boredom) experienced by mobile phone users when they stop using their smartphones because these two symptoms are second only to the core symptoms. Many studies have suggested that anxiety and boredom are highly related to frequent smartphone use and susceptibility to PSU (Elhai, Vasquez, Lustgarten, Levine, \& Hall, 2018; Kim et al., 2019). In early prevention, we should pay attention to improving students' self-control ability and control or monitor the time that students use smartphones to prevent them from excessively using them. An effective way may be parental restrictive mediation related to students' smartphones because previous discussions have indicated that parental restrictive mediation and control exert a protective effect on adolescents' PSU (Chang et al., 2019; Chou \& Chou, 2019; Meeus, Eggermont, \& Beullens, 2019). Ko, Choi, Yang, Lee, and Lee (2015) created a useful mobile service that regards limiting the use of smartphones as a family activity, which emphasizes limits on screen time, enhancements in selfcontrol abilities, and participation with family members.

In addition, previous basic researchers revealed that numerous factors (e.g., parent-child relationship, peer relationship, self-control) can influence adolescents' PSU and suggested that those factors should be considered in PSU treatment or prevention process (Busch \& Mccarthy, 2020). Additionally, some clinical researchers and workers have attempted a host of methods to treat people with PSU, such as the group counseling method (Niu \& Yan, 2017), the mindfulness-based cognitive-behavioral intervention (Yukun et al., 2018), or the proposed exercise rehabilitation treatment (Kim, 2013). Based on our findings, we suggest that clinical interventions for adolescents' PSU in the future can focus on the core symptoms of PSU.

This study has several limitations. First, this network analysis only included one scale to measure problematic smartphone use, which means that it is difficult to capture all aspects of PSU symptoms. Therefore, future studies should analyze other aspects of PSU with different symptoms. Second, the measurement of PSU may be affected by social expectation bias. Studies found that self-reported smartphone use may not be correlated with actual smartphone use (Andrews, Ellis, Shaw, \& Piwek, 2015), which also reminds us to carefully explain our results. Third, this study only used cross-sectional data and cannot infer causality. Although we can affirm the important role of core symptoms based on the network analysis characteristics (Borsboom \& Cramer, 2013; Levinson et al., 2017; Marcus et al., 2018), we should carry out a longitudinal or experimental design for verification in the future. In this way, researchers can judge from the perspective of network analysis whether the direct intervention of adolescents' core symptoms can significantly reduce other symptoms related to these core symptoms, which is conducive to the treatment of peripheral symptoms and the alleviation of PSU. Fourth, the results were based on samples of grade 4 and grade 8 students and, thus, may only apply to adolescents. Future studies should be extended to other age groups to determine whether the results are more adaptable. Finally, it is an oversight that this program does not contain students' age information, and we will add age information in further investigation and study.

\section{CONCLUSIONS}

Loss of control and continued excessive use are core symptoms of PSU in students, and these symptoms exert a strong influence on the connections within the entire network related to PSU. Therefore, future studies on and treatment of adolescents' PSU should focus directly on the core symptoms of PSU to effectively relieve PSU and maximize the effect of the intervention on peripheral symptoms.

Funding sources: This study was funded by a grant from the Fundamental Research Funds for the Central Universities [Grant Number: ZYGX2015J167].

Authors' contribution: $\mathrm{SH}$ study concept and design, analysis and interpretation of data, statistical analysis, writing of the original draft. XL participate in investigation, review and edit the draft, study supervision. YX reviewing and edition of the draft, provide some resources. CZ investigation. YW reviewing and edition of the draft, study supervision, obtained funding.

Additionally: All authors had full access to all data in the study and take responsibility for the integrity of the data and the accuracy of the data analysis.

Conflict of interest: "The authors declare no conflict of interest".

Acknowledgments: The authors would like to thank Mrs. Yuqing Cai, coming from School of Humanities, Tsinghua University, who provided purely technical help and thank all supporting staff at the State Key Laboratory of Cognitive Neuroscience and Learning, Beijing Normal University. Besides, we acknowledge the financial support from the research program of the Collaborative Innovation Center of 
Assessment toward Basic Education Quality at Beijing Normal University. Also, we thank the editor and the anonymous reviewers for they provided some precious suggestions for our work.

\section{REFERENCES}

AERA (2011). AERA code of ethics: American educational research association approved by the AERA council February 2011. Educational Researcher, 40(3), 145-156. https://doi.org/10. 3102/0013189x11410403.

Al-Saggaf, Y., MacCulloch, R., \& Wiener, K. (2018). Trait boredom is a predictor of phubbing frequency. Journal of Technology in Behavioral Science, 4, 245-252. https://doi.org/10.1007/s41347018-0080-4.

Andrews, S., Ellis, D. A., Shaw, H., \& Piwek, L. (2015). Beyond selfreport: Tools to compare estimated and real-world smartphone use. PloS One, 10(10), 1-9. https://doi.org/10.1371/journal. pone.0139004.

APA (2013). Diagnostic and statistical manual of mental disorders. In Pediatria integral. Washington,DC: American Psychiatric Association.

Beard, C., Millner, A. J., Forgeard, M. J. C., Fried, E. I., Hsu, K. J., Treadway, M. T., et al. (2016). Network analysis of depression and anxiety symptom relationships in a psychiatric sample. Psychological Medicine, 46(16), 3359-3369. https://doi.org/10. 1017/S0033291716002300.

Billieux, J., Maurage, P., Lopez-Fernandez, O., Kuss, D. J., \& Griffiths, M. D. (2015). Can disordered mobile phone use be considered a behavioral addiction? An update on current evidence and a comprehensive model for future research. Current Addiction Reports, 2(2), 156-162. https://doi.org/10.1007/ s40429-015-0054-y.

Billieux, J., Schimmenti, A., Khazaal, Y., Maurage, P., \& Heeren, A. (2015). Are we overpathologizing everyday life? A tenable blueprint for behavioral addiction research. Journal of Behavioral Addictions, 4(3), 119-123. https://doi.org/10.1556/2006.4. 2015.009.

Borsboom, D., \& Cramer, A. O. J. (2013). Network analysis: An integrative approach to the structure of psychopathology. Annual Review of Clinical Psychology, 9(1), 91-121. https://doi. org/10.1146/annurev-clinpsy-050212-185608.

Borsboom, D., Cramer, A. O. J., Schmittmann, V. D., Epskamp, S., \& Waldorp, L. J. (2011). The small world of psychopathology. PloS One, 6(11), e27407. https://doi.org/10.1371/journal.pone. 0027407.

Brand, M., Wegmann, E., Stark, R., Müller, A., Wölfling, K., Robbins, T. W., et al. (2019). The Interaction of PersonAffect-Cognition-Execution (I-PACE) model for addictive behaviors: Update, generalization to addictive behaviors beyond internet-use disorders, and specification of the process character of addictive behaviors. Neuroscience and Biobehavioral Reviews, 104, 1-10. https://doi.org/10.1016/j.neubiorev. 2019.06.032.

Brand, M., Young, K. S., \& Laier, C. (2014). Prefrontal control and internet addiction: A theoretical model and review of neuropsychological and neuroimaging findings. Frontiers in Human Neuroscience, 8, 1-13. https://doi.org/10.3389/fnhum. 2014.00375.

Busch, P. A., \& Mccarthy, S. (2020). Antecedents and consequences of problematic smartphone use: A systematic literature review of an emerging research area. In Computers in human behavior. https://doi.org/10.1016/j.chb.2020.106414.

Chang, F. C., Chiu, C. H., Chen, P. H., Chiang, J. T., Miao, N. F., Chuang, H. Y., et al. (2019). Children's use of mobile devices, smartphone addiction and parental mediation in Taiwan. Computers in Human Behavior, 93, 25-32. https://doi.org/10. 1016/j.chb.2018.11.048.

Chen, C., Zhang, K. Z. K., Gong, X., Zhao, S. J., Lee, M. K. O., \& Liang, L. (2017). Examining the effects of motives and gender differences on smartphone addiction. Computers in Human Behavior, 75, 891-902. https://doi.org/10.1016/j.chb.2017.07.002.

Choi, J., Choi, O. J., \& Kim, J. H. (2017). Effects of adolescent smartphone addiction on cybersexual delinquency. Social Behavior and Personality, 45(5), 819-831. https://doi.org/10. 2224/sbp.5916.

Cho, S., \& Lee, E. (2016). Distraction by smartphone use during clinical practice and opinions about smartphone restriction policies: A cross-sectional descriptive study of nursing students. Nurse Education Today, 40, 128-133. https://doi.org/10.1016/j. nedt.2016.02.021.

Chou, H. L., \& Chou, C. (2019). A quantitative analysis of factors related to Taiwan teenagers' smartphone addiction tendency using a random sample of parent-child dyads. Computers in Human Behavior, 99, 335-344. https://doi.org/10.1016/j.chb. 2019.05.032.

Christensen, A. P., Golino, H., \& Silvia, P. J. (2020). A psychometric network perspective on the validity and validation of personality trait questionnaires. European Journal of Personality. https://doi.org/10.1002/per.2265.

CNNIC (2019). The 44th statistical reports on internet development in China. Retrieved from http://www.cac.gov.cn/2019-08/ 30/c_1124939590.htm.

Costantini, G., Epskamp, S., Borsboom, D., Perugini, M., Mõttus, R., Waldorp, L. J., et al. (2015). State of the aRt personality research: A tutorial on network analysis of personality data in R. Journal of Research in Personality, 54, 13-29. https://doi.org/ 10.1016/j.jrp.2014.07.003.

Deursen, A. J. A. M. V., Bolle, C. L., Hegner, S. M., \& Kommers, P. A. M. (2015). Modeling habitual and addictive smartphone behavior the role of smartphone usage types, emotional intelligence, social stress, self-regulation, age, and gender. Computers in Human Behavior, 45, 411-420. https://doi.org/10. 1016/j.chb.2014.12.039.

Elhai, J. D., Vasquez, J. K., Lustgarten, S. D., Levine, J. C., \& Hall, B. J. (2018). Proneness to boredom mediates relationships between problematic smartphone use with depression and anxiety severity. Social Science Computer Review, 36(6), 707-720. https://doi.org/10.1177/0894439317741087.

Fan, L., Liu, X., Wang, B., \& Wang, L. (2017). Interactivity, engagement, and technology dependence: Understanding users' technology utilisation behaviour. Behaviour and Information Technology, 36(2), 113-124. https://doi.org/10.1080/0144929X. 2016.1199051. 
Friedman, J., Hastie, T., \& Tibshirani, R. (2008). Sparse inverse covariance estimation with the graphical lasso. Biostatistics, 9(3), 432-441. https://doi.org/10.1093/biostatistics/kxm045.

Gutiérrez, J. D. S., de Fonseca, F. R., \& Rubio, G. (2016). Cell-phone addiction: A review. Frontiers in Psychiatry, 7, 175. https://doi. org/10.3389/fpsyt.2016.00175.

Hay, C., \& Forrest, W. (2006). The development of self-control: Examining self-control theory's stability thesis. Criminology, 44(4), 739-774. https://doi.org/10.1111/j.1745-9125.2006. 00062.x.

Hormes, J. M., Kearns, B., \& Timko, C. A. (2014). Craving Facebook? Behavioral addiction to online social networking and its association with emotion regulation deficits. Addiction, 109(12), 2079-2088. https://doi.org/10.1111/add.12713.

Horwood, S., \& Anglim, J. (2018). Personality and problematic smartphone use: A facet-level analysis using the five factor model and HEXACO frameworks. Computers in Human Behavior, 85, 349-359. https://doi.org/10.1016/j.chb.2018.04. 013.

Humphries, M. D., \& Gurney, K. (2008). Network "small-worldness": A quantitative method for determining canonical network equivalence. PloS One, 3(4), e0002051. https://doi.org/ 10.1371/journal.pone.0002051.

Jeong, S., Kim, H., Yum, J., \& Hwang, Y. (2016). What type of content are smartphone users addicted to ?: SNS vs. games. Computers in Human Behavior, 54, 10-17. https://doi.org/10. 1016/j.chb.2015.07.035.

Karsay, K., Schmuck, D., Matthes, J., \& Stevic, A. (2019). Longitudinal effects of excessive smartphone use on stress and loneliness: The moderating role of self-disclosure. Cyberpsychology, Behavior, and Social Networking, 22(11), 706-713. https://doi.org/10.1089/cyber.2019.0255.

Kim, H. (2013). Exercise rehabilitation for smartphone addiction. Journal of Exercise Rehabilitation, 9(6), 500-505. https://doi. org/10.12965/jer.130080.

Kim, D., Lee, Y., Lee, J., Nam, J. E. K., \& Chung, Y. (2014). Development of Korean smartphone addiction proneness scale for youth. PloS One, 9(5), 1-8. https://doi.org/10.1371/journal. pone.0097920.

Kim, H. J., Min, J. Y., Min, K. B., Lee, T. J., \& Yoo, S. (2018). Relationship among family environment, self-control, friendship quality, and adolescents' smartphone addiction in South Korea: Findings from nationwide data. PloS One, 13(2), 1-13. https://doi.org/10.1371/journal.pone.0190896.

Kim, S. G., Park, J., Kim, H. T., Pan, Z., Lee, Y., \& McIntyre, R. S. (2019). The relationship between smartphone addiction and symptoms of depression, anxiety, and attention-deficit/ hyperactivity in South Korean adolescents. Annals of General Psychiatry, 18(1), 1-8. https://doi.org/10.1186/s12991-0190224-8.

Ko, M., Choi, S., Yang, S., Lee, J., \& Lee, U. (2015). FamiLync: Facilitating participatory parental mediation of adolescents' smartphone use. Proceedings of the 2015 ACM International Joint Conference on Pervasive and Ubiquitous Computing. New York, NY, 867-878. https://doi.org/10.1145/2750858.2804283.

Kwon, M., Kim, D. J., Cho, H., \& Yang, S. (2013). The smartphone addiction scale: Development and validation of a short version for adolescents. PloS One, 8(12), 1-7. https://doi.org/10.1371/ journal.pone.0083558.

Lapierre, M. A., Zhao, P., \& Custer, B. E. (2019). Short-term longitudinal relationships between smartphone use/dependency and psychological well-being among late adolescents. Journal of Adolescent Health, 65(5), 607-612. https://doi.org/10.1016/j. jadohealth.2019.06.001.

Lee, H., Ahn, H., Choi, S., \& Choi, W. (2014). The SAMS: Smartphone addiction management system and verification. Journal of Medical Systems, 38(1), 1-10. https://doi.org/10. 1007/s10916-013-0001-1.

Lee, J. E., Jang, S. I., Ju, Y. J., Kim, W., Lee, H. J., \& Park, E. C. (2017). Relationship between mobile phone addiction and the incidence of poor and short sleep among Korean adolescents: A longitudinal study of the Korean children \& youth panel survey. Journal of Korean Medical Science, 32(7), 1166-1172. https:// doi.org/10.3346/jkms.2017.32.7.1166.

Leung, L. (2008). Linking psychological attributes to addiction and improper use of the mobile phone among adolescents in Hong Kong. Journal of Children and Media, 2(2), 93-113. https://doi. org/10.1080/17482790802078565.

Levinson, C. A., Zerwas, S., Calebs, B., Forbush, K., Kordy, H., Watson, H., et al. (2017). The core symptoms of bulimia nervosa, anxiety, and depression: A network analysis. Journal of Abnormal Psychology, 126(3), 340-354. https://doi.org/10.1037/ abn0000254.

Liu, Q. Q., Zhou, Z. K., Yang, X. J., Kong, F. C., Niu, G. F., \& Fan, C. Y. (2017). Mobile phone addiction and sleep quality among Chinese adolescents: A moderated mediation model. Computers in Human Behavior, 72, 108-114. https://doi.org/10.1016/j.chb. 2017.02.042.

Marcus, D. K., Preszler, J., \& Zeigler-Hill, V. (2018). A network of dark personality traits: What lies at the heart of darkness? Journal of Research in Personality, 73, 56-62. https://doi.org/10. 1016/j.jrp.2017.11.003.

Martel, M. M., Levinson, C. A., Langer, J. K., \& Psychiatry, J. T. N. (2017). A network analysis of developmental change in ADHD symptom structure from preschool to adulthood. Clinical Psychological Science, 4(6), pp. 988-1001. https://doi.org/10.1177/ 2167702615618664.

Matic, A., Pielot, M., \& Oliver, N. (2015). Boredom-Computer Interaction: Boredom proneness and the use of smartphone. The 2015 ACM International Joint Conference on Pervasive and Ubiquitous Computing (UbiComp '15), New York, NY, pp. 837841.

Meeus, A., Eggermont, S., \& Beullens, K. (2019). Constantly connected: The role of parental mediation styles and self-regulation in pre-and early adolescents' problematic mobile device use. Human Communication Research, 45(2), 119-147. https://doi. org/10.1093/hcr/hqy015.

Montag, C., Wegmann, E., Sariyska, R., Demetrovics, Z., \& Brand, M. (2019). How to overcome taxonomical problems in the study of Internet use disorders and what to do with "smartphone addiction"? Journal of Behavioral Addictions, 1-7. https://doi.org/10.1556/2006.8.2019.59.

Niu, L.-Y., \& Yan, L. (2017). Group counseling for college students mobile phone addiction. The 3rd Annual International 
Conference on Social Science and Contemporary Humanity Development. Guangzhou, GZ, 294-297. https://doi.org/10. 2991/sschd-17.2017.58.

Panova, T., \& Carbonell, X. (2018). Is smartphone addiction really an addiction? Journal of Behavioral Addictions, 1-8. https://doi. org/10.1556/2006.7.2018.49.

Schroeter, R., Oxtoby, J., Johnson, D., \& Steinberger, F. (2015). Exploring boredom proneness as a predictor of mobile phone use in the car. The Annual Meeting of the Australian Special Interest Group for Computer Human Interaction. New York, NY, pp. 465-473.

Seo, D. G., Park, Y., Kim, M. K., \& Park, J. (2016). Mobile phone dependency and its impacts on adolescents' social and academic behaviors. Computers in Human Behavior, 63, 282-292. https://doi.org/10.1016/j.chb.2016.05.026.

Shrivastava, A., \& Shrivastava, M. (2014). Classroom distraction due to mobile phones usage by students: College teachers' perceptions. International Journal of Computer and Information Technology, 03(03), 638-642.

Smith, T. E., Lee, C. A., Martel, M. M., \& Axelrad, M. E. (2016). ODD symptom network during preschool. Journal of Abnormal Child Psychology, 45(4), 743-748. https://doi.org/10.1007/ s10802-016-0196-y.

Soni, R., Upadhyay, R., \& Jain, M. (2017). Prevalence of smart phone addiction, sleep quality and associated behaviour problems in adolescents. International Journal of Research in Medical Sciences, 5(2), 515-519. https://doi.org/10.18203/23206012.ijrms20170142.

Starcevic, V. (2016). Tolerance and withdrawal symptoms amy not be helpful to enhance undertanding of behavioural addictions. Addiction, 111(7), 1307-1308. https://doi.org/10.7723/ antiochreview.75.2.0200.

Tao, R., Huang, X., Wang, J., Zhang, H., Zhang, Y., \& Li, M. (2010). Proposed diagnostic criteria for internet addiction. Addiction, 105(3), 556-564. https://doi.org/10.1111/j.1360-0443.2009. 02828.x.

Thomée, S., Härenstam, A., \& Hagberg, M. (2011). Mobile phone use and stress, sleep disturbances, and symptoms of depression among young adults - A prospective cohort study. BMC Public Health, 11. https://doi.org/10.1186/1471-2458-11-66.

Um, Y. J., Choi, Y. J., \& Yoo, S. Y. (2019). Relationships between smartphone dependency and aggression among middle school students: Mediating and moderating effects of ego-resilience, parenting behaviour, and peer attachment. International Journal of Environmental Research and Public Health, 16(19). https://doi.org/10.3390/ijerph16193534.

Van Borkulo, C., Boschloo, L., Borsboom, D., Penninx, B. W. J. H., Lourens, J. W., \& Schoevers, R. A. (2015). Association of symptom network structure with the course of longitudinal depression. JAMA Psychiatry, 72(12), 1219-1226. https://doi. org/10.1001/jamapsychiatry.2015.2079.

Van Borkulo, C. D., Boschloo, L., Kossakowski, J. J., Tio, P., Schoevers, R. A., Borsboom, D., et al. (2017). Comparing network structures on three aspects: A permutation test. Manuscript Submitted, 34. https://doi.org/10.13140/RG.2.2. 29455.38569.
WHO. (2020). International classification of diseases, 11th revision (ICD-11). Retrieved from https://icd.who.int/browse11/l-m/ en\#/http://id.who.int/icd/entity/1448597234.

Yang, X., Zhou, Z., Liu, Q., \& Fan, C. (2019). Mobile phone addiction and adolescents' anxiety and depression: The moderating role of mindfulness. Journal of Child and Family Studies, 28(3), 822-830. https://doi.org/10.1007/s10826-01801323-2.

Yayan, E. H., Suna Dağ, Y., \& Düken, M. E. (2019). The effects of technology use on working young loneliness and social relationships. Perspectives in Psychiatric Care, 55(2), 194-200. https://doi.org/10.1111/ppc.12318.

Yildirim, C., \& Correia, A.-P. (2015). Understanding nomophobia: A modern age phobia among college students. International Conference on Learning \& Collaboration Technologies, 724-735. https://doi.org/10.1007/978-3-319-20609-7.

Yukun, L., Jiao-Er, D., Wei, L., Jiang, L., Zhang, Y., Mingbo, L., et al. (2018). A pilot study of a group mindfulness-based cognitive-behavioral intervention for smartphone addiction among university students. Journal of Behavioral Addictions, 7(4), 1171-1176. https://doi.org/10.1556/2006.7.2018.103.

Zhang, B., \& Horvath, S. (2005). A general framework for weighted gene co-expression network analysis. Statistical Applications in Genetics and Molecular Biology, 4(1). https://doi.org/10.2202/ 1544-6115.1128.

Zou, Y., Xia, N., Zou, Y., Chen, Z., \& Wen, Y. (2019). Smartphone addiction may be associated with adolescent hypertension: A cross-sectional study among junior school students in China. BMC Pediatrics, 19(1), 1-8. https://doi.org/10.1186/s12887019-1699-9.

\section{APPENDIX}

\section{Appendix I}

Table 2. Demographic materials of grade 8 and grade 4 students

\begin{tabular}{lccc}
\hline Variables & Groups & Grade 8 & Grade 4 \\
\hline Residence & City & $54.59 \%$ & $65.71 \%$ \\
& Rural region & $45.41 \%$ & $34.29 \%$ \\
Only child & Yes & $59.74 \% /$ & $47.23 \%$ \\
& Not & $40.26 \%$ & $52.77 \%$ \\
Left-behind child & Yes & $7.6 \%$ & $10.4 \%$ \\
& Not & $92.4 \%$ & $89.6 \%$ \\
Mothers' education & $<$ College & $93.42 \%$ & $91.77 \%$ \\
& $\geqq$ College & $6.58 \%$ & $8.23 \%$ \\
Father's education & $<$ College & $90.99 \%$ & $93.77 \%$ \\
& $\geqq$ College & $9.01 \%$ & $6.23 \%$ \\
Annual revenue & $<60,000 ¥$ & $71.7 \%$ & $71.1 \%$ \\
& $60,000 ¥-100,000 ¥$ & $20.1 \%$ & $20.3 \%$ \\
& $>100,000 ¥$ & $8.2 \%$ & $8.6 \%$ \\
\hline
\end{tabular}

Note: $¥=\mathrm{RMB}$. 


\section{Appendix II}

Table 3. Detailed and abbreviated descriptions of items on problematic smartphone use scale

\begin{tabular}{|c|c|c|}
\hline Detailed description of items & Function of each item & Reference standards \\
\hline $\begin{array}{l}\text { I1. I have a hard time doing what I have } \\
\text { planned (study, do homework, or go } \\
\text { to afterschool classes) due to using } \\
\text { smartphone. }\end{array}$ & Jeopardize education & $\begin{array}{l}\text { Criterion } 9 \text { of gaming disorder in DSM- } \\
5\end{array}$ \\
\hline $\begin{array}{l}\text { I2. People frequently comment on my } \\
\text { excessive smartphone use. }\end{array}$ & Excessive use & The direct meaning of the item \\
\hline $\begin{array}{l}\text { I3. Family or friends complain that I use } \\
\text { my smartphone too much. }\end{array}$ & Jeopardize a significant relationship & $\begin{array}{c}\text { Criterion } 8 \text { of gambling disorder and } \\
\text { criterion } 9 \text { of Internet gaming disorder } \\
\text { in DMS-5 }\end{array}$ \\
\hline $\begin{array}{l}\text { I4. My smartphone does distract me } \\
\text { from what I am doing. }\end{array}$ & Distraction & Description from Cho \& Lee (2016) \\
\hline $\begin{array}{l}\text { I5. Using a smartphone is more } \\
\text { enjoyable than spending time with } \\
\text { family or friends. }\end{array}$ & Preferences for online interactions & The direct meaning of the item \\
\hline $\begin{array}{l}\text { I6. When I cannot use a smartphone, I } \\
\text { feel like I have lost the entire world. }\end{array}$ & Phobia without a smartphone & $\begin{array}{l}\text { Descriptions from Yildirim \& Correia } \\
\qquad(2015)\end{array}$ \\
\hline $\begin{array}{l}\text { I7. I use a smartphone to make me feel } \\
\text { better when in a bad mood. }\end{array}$ & Relieve bad mood & $\begin{array}{c}\text { Criterion } 8 \text { of Internet gaming disorder } \\
\text { in DSM-5 }\end{array}$ \\
\hline $\begin{array}{l}\text { I8. My life demands cannot be satisfied } \\
\text { without a smartphone. }\end{array}$ & Need for satisfaction & $\begin{array}{l}\text { Descriptions from Chen et al., (2017), } \\
\text { Fan, Liu, Wang, and Wang (2017) }\end{array}$ \\
\hline $\begin{array}{l}\text { I9. I cannot imagine life without a } \\
\text { smartphone. }\end{array}$ & Preoccupation with smartphone & $\begin{array}{c}\text { Criterion } 1 \text { of Internet gaming disorder } \\
\text { in DSM-5 }\end{array}$ \\
\hline $\begin{array}{l}\text { I10. I get anxious and restless when I } \\
\text { am without a smartphone by my side. }\end{array}$ & Anxiety/restless & $\begin{array}{c}\text { Criterion } 2 \text { of Internet gaming disorder } \\
\text { in DSM-5 }\end{array}$ \\
\hline $\begin{array}{l}\text { I11. I feel nervous if I couldn't check my } \\
\text { smartphone or open my smartphone. }\end{array}$ & Nervous & $\begin{array}{c}\text { Criterion } 2 \text { of Internet gaming disorder } \\
\text { in DSM-5 }\end{array}$ \\
\hline $\begin{array}{l}\text { I12. I feel bored if I cannot use a } \\
\text { smartphone. }\end{array}$ & Boredom & Descriptions from Elhai et al., (2018) \\
\hline $\begin{array}{l}\text { I13. I try cutting my smartphone use } \\
\text { time, but I fail. }\end{array}$ & Loss of control & $\begin{array}{l}\text { Criteria of gaming disorder in ICD-11; } \\
\text { criterion } 4 \text { of Internet gaming disorder } \\
\text { in DSM-5 }\end{array}$ \\
\hline $\begin{array}{l}\text { I14. I find that the time I spend on my } \\
\text { smartphone is longer than planned. }\end{array}$ & Loss of control & $\begin{array}{c}\text { Criterion } 4 \text { of Internet gaming disorder } \\
\text { in DSM-5 }\end{array}$ \\
\hline $\begin{array}{l}\text { I15. Even when I think I should stop, I } \\
\text { continue to use my smartphone too } \\
\text { much. }\end{array}$ & Loss of control & $\begin{array}{l}\text { Criteria of gaming disorder in ICD-11; } \\
\text { criterion } 4 \text { of Internet gaming disorder } \\
\text { in DSM-5 }\end{array}$ \\
\hline $\begin{array}{l}\text { I16. Spending a lot of time on my } \\
\text { smartphone has become a habit. }\end{array}$ & Continued excessive use & $\begin{array}{c}\text { Criterion } 6 \text { of Internet gaming disorder } \\
\text { in DSM-5 }\end{array}$ \\
\hline
\end{tabular}




\section{Appendix III}

Table 4. Partial correlation matrix related to problematic smartphone use in grade 8 students

\begin{tabular}{|c|c|c|c|c|c|c|c|c|c|c|c|c|c|c|c|c|}
\hline & I1 & I2 & I3 & I4 & I5 & I6 & I7 & I8 & I9 & I10 & I11 & I12 & I13 & I14 & I15 & I16 \\
\hline I1 & 0 & 0.018 & 0.037 & 0.175 & 0.008 & 0.088 & 0 & 0 & -0.015 & 0 & 0 & -0.003 & 0.247 & 0.174 & 0.056 & 0.047 \\
\hline I2 & 0.018 & 0 & 0.397 & 0.004 & 0.001 & 0 & 0.124 & 0 & 0 & 0.011 & 0.014 & 0.006 & 0.055 & 0.169 & 0.051 & 0.070 \\
\hline I3 & 0.037 & 0.397 & 0 & 0.073 & 0.010 & 0 & 0.060 & 0.013 & 0 & 0 & 0.020 & 0.047 & 0.023 & 0.024 & 0.110 & 0.034 \\
\hline I4 & 0.175 & 0.004 & 0.073 & 0 & 0 & 0 & 0.009 & 0.003 & -0.006 & 0 & 0.022 & 0.087 & 0.060 & 0.124 & 0.096 & 0.204 \\
\hline I5 & 0.008 & 0.001 & 0.010 & 0 & 0 & 0.049 & 0.005 & 0.068 & 0.139 & 0.022 & 0.027 & 0.02 & 0.012 & 0.010 & 0.032 & 0.039 \\
\hline I6 & 0.088 & 0 & 0 & 0 & 0.049 & 0 & 0.008 & 0.194 & 0.196 & 0.313 & 0.079 & 0.024 & 0.037 & 0.008 & 0.001 & 0.018 \\
\hline I7 & 0 & 0.124 & 0.060 & 0.009 & 0.005 & 0.008 & 0 & 0.016 & 0.055 & 0 & 0.073 & 0.119 & 0.016 & 0.028 & 0.139 & 0 \\
\hline I8 & 0 & 0 & 0.013 & 0.003 & 0.068 & 0.194 & 0.016 & 0 & 0.123 & 0.110 & 0.123 & 0.233 & 0 & 0 & 0.014 & 0.129 \\
\hline I9 & -0.015 & 0 & 0 & -0.006 & 0.139 & 0.196 & 0.055 & 0.123 & 0 & 0.106 & 0.044 & 0.070 & 0.112 & 0 & 0.013 & 0.027 \\
\hline $\mathrm{I} 10$ & 0 & 0.011 & 0 & 0 & 0.022 & 0.313 & 0 & 0.110 & 0.106 & 0 & 0.296 & 0.052 & 0.020 & 0.087 & 0 & 0.033 \\
\hline I11 & 0 & 0.014 & 0.020 & 0.022 & 0.027 & 0.079 & 0.073 & 0.123 & 0.044 & 0.296 & 0 & 0.051 & 0.019 & 0 & 0.100 & 0.056 \\
\hline I12 & -0.003 & 0.006 & 0.047 & 0.087 & 0.020 & 0.024 & 0.119 & 0.233 & 0.070 & 0.052 & 0.051 & 0 & 0 & 0.011 & 0.055 & 0.230 \\
\hline I13 & 0.247 & 0.055 & 0.023 & 0.060 & 0.012 & 0.037 & 0.016 & 0 & 0.112 & 0.020 & 0.019 & 0 & 0 & 0.101 & 0.119 & 0.066 \\
\hline I14 & 0.174 & 0.169 & 0.024 & 0.124 & 0.010 & 0.008 & 0.028 & 0 & 0 & 0.087 & 0 & 0.011 & 0.101 & 0 & 0.162 & 0.111 \\
\hline I15 & 0.056 & 0.051 & 0.110 & 0.096 & 0.032 & 0.001 & 0.139 & 0.014 & 0.013 & 0 & 0.100 & 0.055 & 0.119 & 0.162 & 0 & 0.116 \\
\hline I16 & 0.047 & 0.070 & 0.034 & 0.204 & 0.039 & 0.018 & 0 & 0.129 & 0.027 & 0.033 & 0.056 & 0.230 & 0.066 & 0.111 & 0.116 & 0 \\
\hline
\end{tabular}

\section{Appendix IV}

Table 5. Partial correlation matrix related to problematic smartphone use in grade 4 students

\begin{tabular}{|c|c|c|c|c|c|c|c|c|c|c|c|c|c|c|c|c|}
\hline & I1 & I2 & I3 & I4 & I5 & I6 & I7 & I8 & I9 & I10 & I11 & I12 & I13 & I14 & I15 & I16 \\
\hline I1 & 0 & 0.043 & 0.047 & 0.148 & 0.023 & 0.071 & 0 & -0.003 & 0 & 0.033 & 0.017 & 0 & 0.215 & 0.162 & 0.047 & 0.021 \\
\hline I2 & 0.043 & 0 & .336 & 0.021 & 0 & 0 & 0.124 & 0.002 & 0 & 0.003 & 0.034 & 0.012 & 0.058 & 0.168 & 0.065 & 0.058 \\
\hline I3 & 0.047 & 0.336 & 0 & 0.073 & 0.001 & 0 & .051 & 0.025 & 0 & 0 & 0.025 & 0.040 & 0.024 & 0.046 & 0.088 & 0.030 \\
\hline I4 & 0.148 & 0.021 & 0.073 & 0 & 0 & 0 & 0.025 & 0.014 & -0.002 & 0.003 & 0.028 & 0.120 & 0.059 & 0.099 & 0.071 & 0.213 \\
\hline I5 & 0.023 & 0 & 0.001 & 0 & 0 & 0.063 & 0.023 & 0.054 & 134 & 0.051 & 0.035 & 0.015 & 0.012 & 0.032 & 0.047 & 0.031 \\
\hline I6 & 0.071 & 0 & 0 & 0 & 0.063 & 0 & 0.004 & 0.172 & 0.162 & 0.311 & 0.092 & 0.037 & 0.062 & 0.030 & 0.016 & 0.029 \\
\hline I7 & 0 & 0.124 & 0.051 & 0.025 & 0.023 & 0.004 & 0 & 0.017 & 0.055 & 0 & 0.063 & 0.138 & 0.039 & 0.043 & 0.152 & 0.004 \\
\hline I8 & -0.003 & 0.002 & 0.025 & 0.014 & 0.054 & 0.172 & 0.017 & 0 & 0.099 & 0.113 & 0.093 & 0.241 & 0 & 0 & 0.013 & 0.146 \\
\hline I9 & 0 & 0 & 0 & -0.002 & 0.134 & 0.162 & 0.055 & 0.099 & 0 & 0.106 & 0.056 & 0.065 & 0.117 & 0 & 0.022 & 0.022 \\
\hline I10 & 0.033 & 0.003 & 0 & 0.003 & 0.051 & 0.311 & 0 & 0.113 & 0.106 & 0 & 0.246 & 0.041 & 0.014 & 0.090 & 0.004 & 0.030 \\
\hline I11 & 0.017 & 0.034 & 0.025 & 0.028 & 0.035 & 0.092 & 0.063 & 0.093 & 0.056 & 0.246 & 0 & 0.065 & 0.012 & 0.011 & 0.097 & 0.047 \\
\hline I12 & 0 & 0.012 & 0.040 & 0.120 & 0.015 & 0.037 & 0.138 & 0.241 & 0.065 & 0.041 & 0.065 & 0 & 0.018 & 0.011 & 0.055 & 0.204 \\
\hline I13 & 0.215 & 0.058 & 0.024 & 0.059 & 0.012 & 0.062 & 0.039 & 0 & 0.117 & 0.014 & 0.012 & 0.018 & 0 & 0.082 & 0.099 & 0.069 \\
\hline I14 & 0.162 & 0.168 & 0.046 & 0.099 & 0.032 & 0.030 & 0.043 & 0 & 0 & 0.090 & 0.011 & 0.011 & 0.082 & 0 & 0.145 & 0.117 \\
\hline I15 & 0.047 & 0.065 & 0.088 & 0.071 & 0.047 & 0.016 & 0.152 & 0.013 & 0.022 & 0.004 & 0.097 & 0.055 & 0.099 & 0.145 & 0 & 0.137 \\
\hline I16 & 0.021 & 0.058 & 0.030 & 0.213 & 0.031 & 0.029 & 0.004 & 0.146 & 0.022 & 0.030 & 0.047 & 0.204 & 0.069 & 0.117 & 0.137 & 0 \\
\hline
\end{tabular}

